\title{
Changes in the porosity of bulk graphite according to the viscosity of resin for impregnation
}

\author{
Sang-Min Lee ${ }^{1}$, Dong-Su Kang ${ }^{1}$, Hye-Sung Kim ${ }^{2}$ and Jea-Seung Roh ${ }^{1, s}$ \\ ${ }^{1}$ School of Advanced Materials and Systems Engineering, Kumoh National Institute of Technology, Gumi 730-701, Korea \\ ${ }^{2}$ Department of Nanomaterials Engineering, College of Nanoscience and Nanotechnology, Pusan National University, Miryang 627- \\ 706, Korea
}

\section{Article Info}

Received 26 January 2015 Accepted 10 March 2015

*Corresponding Author

E-mail: jsroh@kumoh.ac.kr

\section{Open Access}

DOI: http://dx.doi.org/

10.5714/CL.2015.16.2.132

This is an Open Access article distributed under the terms of the Creative Commons Attribution Non-Commercial License (http://creativecommons.org/licenses/ by-nc/3.0/) which permits unrestricted non-commercial use, distribution, and reproduction in any medium, provided the original work is properly cited.

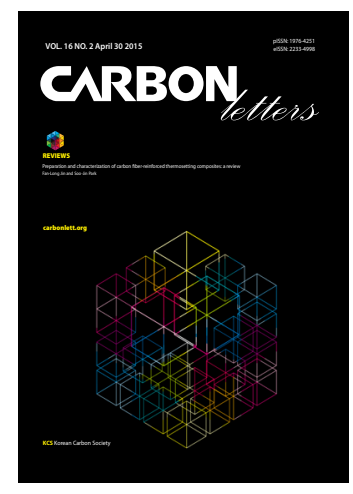

http://carbonlett.org

pISSN: 1976-4251

elSSN: 2233-4998

Copyright $\odot$ Korean Carbon Society

\begin{abstract}
When manufacturing bulk graphite, pores develop within the bulk during the carbonization process due to the volatile components of the fillers and the binders. As a result, the physical properties of bulk graphite are inferior to the theoretical values. Impregnants are impregnated into the pores generated in the carbonization process through pressurization and/or depressurization. The physical properties of bulk graphite that has undergone impregnation and re-carbonization processes are outstanding. In the present study, a green body was manufactured by molding with natural graphite flakes and phenolic resin at $45 \mathrm{MPa}$. Bulk graphite was manufactured by carbonizing the green body at 700 and it was subsequently impregnated with impregnants having viscosity of $25.0 \mathrm{cP}, 10.3 \mathrm{cP}$, and $5.1 \mathrm{cP}$, and the samples were re-carbonized at $700^{\circ} \mathrm{C}$. The above process was repeated three times. The open porosity of bulk graphite after the final process was $22.25 \%, 19.86 \%$, and $18.58 \%$ in the cases of using the impregnant with viscosity of $25.0 \mathrm{cP}, 10.3 \mathrm{cP}$, and $5.1 \mathrm{cP}$, respectively.
\end{abstract}

Key words: bulk graphite, impregnation, impregnant, viscosity, pores

\section{Introduction}

While many ceramic materials possess self-sinterability, cokes, which are the main material of bulk graphite, do not sinter, and hence are used after having been mixed with binders [1]. With petroleum pitch or coal tar pitch as a starting material, cokes used as fillers undergo a state of green cokes, which are generated from heating at approximately $500^{\circ} \mathrm{C}$, and are manufactured through thermal treatment at $1200^{\circ} \mathrm{C}-1400^{\circ} \mathrm{C}[2,3]$. The manufactured cokes are mixed with binders having high carbonization yields. Subsequently, bulk graphite is manufactured through molding, carbonization, impregnation, graphitization, and high purity processes. During the carbonization process numerous pores are generated inside the bulk graphite due to the release of volatile components contained in the binders. The material's physical properties, such as its mechanical strength, are degraded due to these pores [4-6]. To fill the pores generated in the carbonization process, impregnants are penetrated through pressurization and/or depressurization and samples are re-carbonized. The impregnation process is an indispensable part of the bulk graphite manufacture process because it reduces the porosity and consequently improves the density, strength, and electric conductivity of the product [7]. Impregnant viscosity, impregnant surface tension, angle of contact at which impregnation occurs, reactivity during thermal treatment, and carbonization yield can be controlled as variables determining the impregnation effect $[8,9]$.

In the present study, after manufacturing bulk graphite by using natural graphite and phenolic resin, the porosity reduction effect according to the viscosity of the impregnants was examined. As an impregnant, phenolic resin was diluted in ethanol (henceforth "solvent") to adjust the viscosity, and then used. After subjecting the manufactured bulk graphite to depressurized impregnation three times, changes in the density and the porosity were measured. 


\section{Experimental Procedure}

\subsection{Raw materials and preparations}

For the filler used in the present study, HCP-198 natural graphite flakes (Hyundai Coma Industry, Inc.) were used. For the binder, CB-8081 phenolic resin (Kangnam Chemical Co., Ltd.) was used. The mixed powder was molded at $45 \mathrm{Mpa}$ to manufacture the green body. The manufactured green body was carbonized for $1 \mathrm{~h}$ at $700^{\circ} \mathrm{C}$ in a nitrogen atomoshere [10].

\subsection{Impregnation}

The phenolic resin and the solvent were mixed at weight ratios of 6:4 (henceforth "IM-A"), 5:5 (henceforth "IM-B"), and 4:6 (henceforth "IM-C") to prepare the impregnants; a viscometer (Brookfield; DV-II+ Pro) was used to measure the viscosity. Pores generated by the release of impurities from the filler and volatile components from the binder were filled using impregnation and re-carbonization processes [10]. Depressurized impregnation was performed for 30 minutes and this process was repeated three times.

\subsection{Density and porosity measurement}

Changes in the density and the porosity according to the types of impregnants were measured using the Archimedes method (ISO 18754: 2003). The volumetric density, including the volume of the bulk graphite's open pores and closed pores (henceforth "density"), was measured. The open porosity (henceforth "porosity") was measured to confirm the impregnation effect. This is necessary because impregnation occurs in channels linked to open pores and thus open porosity data must be analyzed to confirm the impregnation effect according to the type of impregnant $[10,11]$.

\section{Results and Discussion}

\subsection{As carbonized}

When the green body manufactured with mixed powder was carbonized at $700^{\circ} \mathrm{C}$, the density of bulk graphite was $1.66 \mathrm{~g} /$ $\mathrm{cm}^{3}$ and the porosity was $23.40 \%$.

Table 1. Measurements of the viscosity according to the mixture ratios of phenolic resin and solvent ( 5 measurements and average values)

\begin{tabular}{ccccccccc} 
& \multicolumn{6}{c}{ Weight ratio } & \multicolumn{6}{c}{ Viscosity (cP) } \\
\cline { 2 - 9 } Sample & $\begin{array}{c}\text { Phenolic } \\
\text { Resin }\end{array}$ & Ethanol & 1 & 2 & 3 & 4 & 5 & Avg. \\
\hline IM-A & 6 & 4 & 25.6 & 25.9 & 25.3 & 24.3 & 24.1 & 25.0 \\
IM-B & 5 & 5 & 10.3 & 9.82 & 9.85 & 10.8 & 10.6 & 10.3 \\
IM-C & 4 & 6 & 5.27 & 5.23 & 5.14 & 5.04 & 5.01 & 5.1 \\
\hline
\end{tabular}

\subsection{Impregnation}

Table 1 shows the average values after five measurements of the viscosity, according to the mixture ratios of phenolic resin and the solvent. The viscosity was $25.0 \mathrm{cP}$ for IM-A, $10.3 \mathrm{cP}$ for IM-B, and $5.1 \mathrm{cP}$ for IM-C. As the proportion of the solvent was increased, the viscosity was confirmed to decrease.

\subsection{Density and porosity}

Fig. 1 shows the measurement results of the density and the porosity according to the impregnant type and the average values of five measurements for each sample. After being impregnated three times, the density compared to that before impregnation tended to increase according to the decrease in impregnant viscosity. The density of bulk graphite impregnated with IM-A increased by $1.23 \%$, that of graphite impregnated with IM-B increased by $2.47 \%$, and that of bulk graphite impregnated with IM-C increased by $3.70 \%$. In addition, the porosity of bulk graphite impregnated three times and then impregnated with IM-A was $22.25 \%$; the sample with IM-B had a value of $19.86 \%$ and the sample with IM-C had a value of $18.58 \%$, thus showing that with lower impregnant viscosity, the porosity accordingly decreased. With an increase in the number of times impregnation was performed, pores were confirmed to be better filled. With lower impregnant viscosity, the effect of the impregnants penetrating into the pores was accordingly greater. Table 2 shows the density and the porosity according to the impregnant viscosity. The Hagen-Poiseuille equation represents the depth to
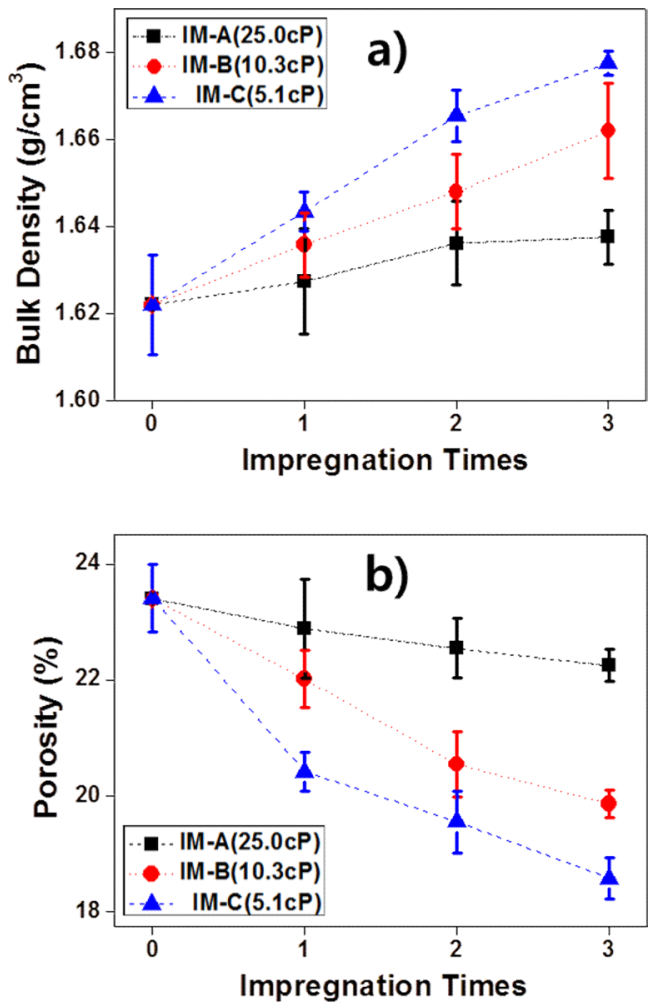

Fig. 1. Changes in the bulk density and the open porosity. 
Table 2. Summary of bulk density and open porosity measurements

\begin{tabular}{cccc} 
Impregnants & Impregnation & $\begin{array}{c}\text { Bulk density } \\
(\text { Avg. g/cm }\end{array}$ & $\begin{array}{c}\text { Porosity of open pores } \\
(\text { Avg. \%) }\end{array}$ \\
\hline- & Before & 1.662 & 23.40 \\
\hline \multirow{2}{*}{ IM-A } & 1 time & 1.627 & 22.88 \\
& 2 times & 1.636 & 22.60 \\
& 3 times & 1.638 & 22.25 \\
\hline \multirow{2}{*}{ IM-B } & 1 time & 1.636 & 22.01 \\
& 2 times & 1.648 & 20.55 \\
& 3 times & 1.660 & 19.86 \\
\hline \multirow{2}{*}{ IM-C } & 1 time & 1.643 & 20.46 \\
& 2 times & 1.665 & 19.55 \\
& 3 times & 1.677 & 18.58 \\
\hline
\end{tabular}

which the solution having viscosity is penetrated, as given in Eq. (1) [12]:

$$
\ell^{2}=(\gamma \cdot r \cdot \cos \theta \cdot t) / 2 \eta
$$

$\ell$ : penetration depth; $\gamma$ : surface tension of the solution; $r$ : radii of the capillaries; $\theta$ : angle of contact; t: infiltration time; $\eta$ : viscosity of the solution

Because the penetration depth was inversely proportionate to the solution viscosity, impregnants with low viscosity were deemed to have a considerable penetration effect into the pores.

\section{Conclusions}

The following conclusions were obtained regarding the effect of impregnant viscosity on changes in the porosity when manufacturing bulk graphite using natural graphite and phenolic resin. When the density and the porosity of bulk graphite manufactured using impregnants with disparate levels of viscosity were analyzed, compared to the density before impregnation, after being impregnated three times, the density increased by $1.23 \%$ for bulk graphite impregnated with IM-A, by $2.47 \%$ for bulk graphite impregnated with IM-B, and by $3.70 \%$ for bulk graphite impregnated with IM-C.

The porosity before impregnation was $23.40 \%$; the porosity of bulk graphite impregnated with IM-A after being impregnated three times was $22.25 \%$, that of bulk graphite impregnated with IM-B was $19.86 \%$, and that of bulk graphite impregnated with IM-C was $18.58 \%$. Thus there was a decreasing trend with lower impregnant viscosity.

In the present study, the porosity reduction effect was considerable for bulk graphite impregnated with IM-C. In the future, the carbonization yield according to the type of impregnant and the distribution of pore size of the impregnated bulk graphite will be analyzed to develop methods for the impregnation process in the production of high-density bulk graphite.

\section{References}

[1] White JL, Price RJ. The formation of mesophase microstructures during the pyrolysis of selected coker feedstocks. Carbon, 12, 321 (1974). http://dx.doi.org/10.1016/0008-6223(74)90073-6.

[2] Zheng T, Reimers JN, Dahn JR. Effect of turbostratic disorder in graphitic carbon hosts on the intercalation of lithium. Phys Rev B, 51, 734 (1995). http://dx.doi.org/10.1103/PhysRevB.51.734.

[3] Otani S, Oya A. Carbon products prepared from variant pitch materials. VIII. The preparation of isotropic pitch carbon with a high density. Bull Chem Soc Jpn, 46, 314 (1973). http://dx.doi.org/10.1246/ bcsj.46.314.

[4] Kim JY, Lee SY, Choi JH, Park YD. Preparation of carbon solid from dormant mesophase pitch without using a binder. J Korean Ceram Soc, 29, 396 (1992).

[5] Chung HJ, Lim YS. Preparation and characterization of mesophase pitches as a matrix precursor of carbon fiber reinforced carbon composite. J Korean Ceram Soc, 33, 1387 (1996).

[6] Bhatia G, Aggarwal RK. Influence of processed carbon black in the filler composition on the characteristics of baked carbon mixes. J Mater Sci, 16, 1757 (1981). http://dx.doi.org/10.1007/ BF00540621.

[7] Youm HN, Kim KJ, Lee JM, Chung YJ. Effects of impregnation on the manufacture of high density carbon materials. J Korean Ceram Soc, 30, 852 (1993).

[8] Gao S, Tanada S, Abe I, Kitagawa M, Matsubara Y. Absorption of organic compounds on surface-modified activated carbons in aqueous solution. TANSO, 163, 138 (1994).

[9] Matzinos PD, Patrick JW, Walker A. Coal-tar pitch as a matrix precursor for 2-D C/C composites. Carbon, 34, 639 (1996). http:// dx.doi.org/10.1016/0008-6223(96)00018-8

[10] Lee SM, Kang DS, Kim WS, Roh JS. Fabrication of isotropic bulk graphite using artificial graphite scrap. Carbon Lett, 15, 142 (2014). http://dx.doi.org/10.5714/CL.2014.15.2.142.

[11] Han YS, Kim HJ, Shin YS, Park JK, Ko JC. Silver coating on the porous pellets from porphyry rock and application to an antibacterial media. J Korean Ceram Soc, 46, 16 (2009). http://dx.doi org/10.4191/KCERS.2009.46.1.016.

[12] Nagai B, Matsumoto O, Isobe T, Nishiumi Y. Wear mechanism of castable for steel ladle by slag. Taikabutsu Overseas, 12, 15 (1992). 